\title{
Tangibilidade da complexidade
}

Paula Broeiro*

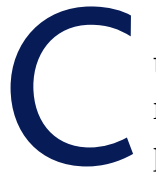

omplexidade é um termo versátil com múltiplas aplicações e matizes dentro do domínio da saúde e dos cuidados de saúde. A complexidade dos doentes é potencialmente mais relevante do que a complexidade do diagnóstico, porque está frequentemente ligada a determinantes sociais de saúde e à necessidade de integração horizontal de cuidado, sendo indispensáveis o trabalho em equipa multiprofissional e uma articulação social eficientes. ${ }^{1}$ Numa das muitas experiências de vida pessoais e profissionais conheci uma enfermeira recémchegada a uma unidade de cuidados na comunidade (UCC), vinda de uma unidade de cuidados intensivos (UCI) hospitalares que ilustrou a sua perceção de complexidade em UCC: na UCI quando o doente descompensa, o dispositivo toca o alarme; quando acaba o turno, o doente fica entregue a outra equipa; em UCC, os profissionais têm que desenvolver competências para perceber os pequenos sinais de descompensação e deixar os doentes entregues a cuidadores muitas vezes impreparados e sem recursos.

O conceito de complexidade confunde-se com o uso corrente da palavra complexidade e, em medicina, com o conceito de gravidade e alta tecnologia. $O$ termo tem sido utilizado indiscriminadamente para designar complexidade do doente ou complexidade do cuidado. ${ }^{1} \mathrm{Em}$ medicina geral e familiar (MGF), a complexidade decorrente da teoria dos sistemas tem sido largamente estudada e é entendida como mais abrangente que o doente complexo.

Os sistemas adaptativos complexos são definidos como o conjunto de diferentes sistemas e elementos que interagem de forma não-linear, apresentando comportamentos que não podem ser explicados apenas pelo comportamento dos seus componentes isolados (reducionismo) ${ }^{2-3} \mathrm{~A}$ interrelação entre elementos indissociáveis dum sistema complexo pode manifestarse como propriedade ou recurso desse sistema (e.g., família), o que significa que um sistema não pode ser entendido pelos seus componentes individuais isolados,

*Directora da Revista Portuguesa de Medicina Geral e Familiar mas deve incluir as interrelações presentes, mesmo que com pesos variáveis. ${ }^{4}$ Em medicina, uma pessoa doente é mais que o conjunto dos seus diagnósticos e terapêuticas e requer uma abordagem holística que inclua a compreensão da singularidade resultante da interceção de sistemas (e.g., individual, familiar, social e sistema de saúde). Estes conceitos justificam a inadequação da aplicabilidade a um doente com multimorbilidade de normas orientadas para a doença. $O$ médico de família não é "super-poli-mini-especialista"; é, sim, o médico que faz a integração sinérgica da medicina, epidemiologia, psicologia e da antropologia, ${ }^{5}$ bem como dos cuidados e cuidadores. É no cuidado individual que convergem as complexidades do doente e do cuidar.

As teorias explicativas de sistemas complexos surgiram durante a segunda metade do século dezanove nas ciências básicas, como a física, a matemática, a química e outras. ${ }^{2}$ Um dos benefícios da ciência da complexidade é a sua capacidade de ultrapassar a fragmentação e as limitações que se impõem à compreensão da etiologia, diagnóstico e tratamento da doença. ${ }^{2}$ Numa revisão narrativa histórica recente é descrito o desenvolvimento da MGF na sua relação com as teorias de sistemas adaptativos complexos. Inicialmente estas teorias forneceram um quadro de referência quanto à saúde, doença e vivência da doença. Nos últimos 15 anos expandiram-se às organizações, conduzindo a uma tomada de consciência crescente da importância das interações entre os diversos sistemas e, em consequência, a mudanças na prestação de cuidados, na organização dos serviços e na perspetivação das reformas de saúde. ${ }^{2}$

McWhinney nunca escreveu explicitamente sobre o projeto do sistema de saúde, mas sobre o significado da MGF e com ele aprendemos o significado da vivência da doença e a necessidade de cuidados primários de alta qualidade para a saúde dos pacientes individuais. ${ }^{6}$ O contributo da escola Canadiana de McWhinney tem subjacente a filosofia sistémica centrada no paciente e na relação médico-paciente e veio transformar o modelo biomédico tradicional. ${ }^{6} \mathrm{~A}$ metáfora mecanicista cartesiana do "corpo como máquina" tem sido contra- 
riada pela organicista que considera o corpo um sistema complexo adaptativo. ${ }^{6-7} \mathrm{O}$ método clínico centrado no paciente, proposto há longos anos, era já expressão da complexidade: requer que entendamos não só a doença biológica, mas também a experiência individual de doença, contexto social amplo (família, comunidade, época) e os determinantes da saúde, a par do encontro de plataformas de entendimento, da melhoria da relação ${ }^{6}$ e da articulação de cuidados (e.g., sistemas de saúde).

Em cada consulta o paciente apresenta a sua história, construída através da sua experiência pessoal de doença, de vida e contexto dos cuidados. Em simultâneo, o médico recorre ao seu conhecimento clínico, experiência e recursos externos de forma a fazer uma avaliação e construir um plano integrado. ${ }^{5}$ Perante situações de maior complexidade, o médico pode ter necessidade de recorrer a suportes de apoio à decisão clínica, discutir o caso com os pares ou, se garantida a continuidade de cuidado, utilizar o tempo como recurso. ${ }^{5}$ É vital adotar uma abordagem holística, partilhada com os doentes, respeitando as diferenças e escolhas individuais e equilibrando "bom cuidado" /"melhor cuidado", em especial quando este último é irrealista. ${ }^{5}$ A MGF é uma disciplina baseada em evidência, que requer o desenvolvimento de atitudes e competências de comunicação, presença, autenticidade, empatia. ${ }^{5}$ Perante um doente complexo, que requer cuidados complexos e exige a concretização daquelas atitudes e competências, poderá ser mais eficiente um tempo de consulta adaptado e suficiente (consultas mais longas) do que um tempo programado pelo relógio (tempo padrão destinado à consulta). ${ }^{5}$

A complexidade em MGF é conferida pela abrangência do cuidar (independente da idade, patologia, condição social e das suas interações) ${ }^{8}$ integrado num sistema de saúde (articulação vertical) e numa comunidade (articulação horizontal). É esta complexidade que diferencia a MGF e que exige a execução de diversas tarefas por consulta, tornando necessário mais tempo por consulta. ${ }^{8}$ As medidas de processo orientadas por problemas únicos (e.g., programa de diabetes) não refletem os resultados em saúde (e.g., qualidade de vida, mortalidade). ${ }^{8}$ Existe, pois, desconexão entre o processo de cuidar e os resultados esperados (e.g., métricas indicadores). ${ }^{8}$ A avaliação em complexidade aponta para os limites do desenho de gestão orientado para a doença e realça a necessidade de mudança de paradigma para uma gestão centrada na pessoa, tendo em conta os conhecimentos atuais sobre os sistemas adaptativos complexos. ${ }^{1}$ A medicina moderna colocou em manifesto o paradoxo de que cuidados de elevado custo não se refletiram em cuidados de superior qualidade, isto é, o esforço para melhorar as partes (cuidados baseados em evidência para doenças específicas) não melhoraram o todo (a saúde das pessoas e populações). ${ }^{9}$

Os sistemas de saúde não estão ainda projetados em torno da complexidade; são, pois, inadequados para a doença crónica complexa, multimorbilidade, doença mental e instabilidade socioeconómica. Não incluem o (aparentemente) inesperado, nem o paradoxal, próprios dos sistemas adaptativos e não permitem a emergência do ainda desconhecido. ${ }^{3}$

Quando se avalia complexidade existem pelo menos quatro domínios que, segundo o instrumento INTERMED, importa considerar: biológico (gravidade, cronicidade e incerteza diagnóstica); psicológico (antecedentes e história psiquiátrica); social (suporte social e estabilidade residencial); cuidados de saúde (sistema de saúde). ${ }^{1}$ Um sistema projetado em torno de complexidade faria a integração vertical (e.g., cuidados primários e diferenciados) e horizontal de cuidados (e.g., saúde e sociedade), privilegiando a interação entre os diferentes agentes do cuidar. ${ }^{6} \mathrm{O}$ pensamento linear dos programas de gestão integrada da doença (e.g., insuficiência renal) seria o triunfo sobre a incerteza; contudo, elimina da equação a situação particular de cada pessoa (e.g., multimorbilidade, crenças, valores e expectativas), tornando os cuidados insatisfatórios ${ }^{6}$ e ineficientes. Se é verdade que não se pode melhorar o que não se mede, então temos que pensar muito sobre o que medimos quando optamos por definir o sucesso numa área da saúde. ${ }^{6}$ Segundo McWhinney, deveríamos medir o que importa e não apenas o que é facilmente quantificável. ${ }^{6}$

Desde sempre recorremos a instrumentos para lidar com a complexidade: fluxogramas, tabelas de várias entradas, diagramas cartesianos (e.g., diagrama de Stacey $)^{10}$ ou mapas (e.g., mapa de problemas) ${ }^{11}$. Todas estas ferramentas ajudam-nos a compreender a realidade; contudo, são meras aproximações da realidade de 
acordo com uma ou mais perspetivas de análise. A abordagem instrumental da complexidade revela-se uma tarefa apenas tangível por se tratar de uma realidade pluridimensional. Os desafios socioecológicos atuais conduzem a que a complexidade deva ser interiorizada não apenas como conceito "complexidade intelectual" (saber), mas como vivência "complexidade vivida" (ser e agir). ${ }^{5}$

Em MGF, o método clínico centrado no paciente, a medicina narrativa e o trabalho em equipa são ferramentas indispensáveis à definição de um plano individualizado de cuidados em contexto de complexidade.

\section{REFERÊNCIAS BIBLIOGRÁFICAS}

1. Peek CJ, Baird MA, Coleman E. Primary care for patient complexity, not only disease. Fam Syst Health. 2009;27(4):287-302.

2. Sturmberg JP, Martin CM, Katerndahl DA. Systems and complexity thinking in the general practice literature: an integrative, historical narrative review. Ann Fam Med. 2014;12(1):66-74.

3. Plsek PE, Greenhalgh T. Complexity science: the challenge of comple- xity in health care. BMJ. 2001;323(7313):625-8.

4. Kannampallil TG, Schauer GF, Cohen T, Patel VL. Considering complexity in healthcare systems. J Biomed Inform. 2011;44(6):943-7.

5. Ventres WB. How I think: perspectives on process, people, politics, and presence. J Am Board Fam Med. 2012;25(6):930-6.

6. Martin D, Pollack K, Woollard RF. What would an lan McWhinney health care system look like? Can Fam Physician. 2014;60(1):17-9.

7. Jayasinghe $\mathrm{S}$. Complexity science to conceptualize health and disease: is it relevant to clinical medicine? Mayo Clin Proc. 2012;87(4):314-9.

8. Bowman MA. The complexity of family medicine care. J Am Board Fam Med. 2011;24(1):4-5.

9. Stange KC, Ferrer RL. The paradox of primary care. Ann Fam Med. 2009; 7(4):293-9.

10. Stacey R, Griffin DS. Complexity and management: fad or radical challenge to systems thinking? London: Routledge; 2000. ISBN 9780415247610

11. Broeiro P, Ramos V, Barroso R. O mapa de problemas: um instrumento para lidar com a morbilidade multipla. Rev Port Clin Geral. 2007;23(2):209-15.

\section{ENDEREÇO PARA CORRESPONDÊNCIA}

director@rpmgf.pt 